
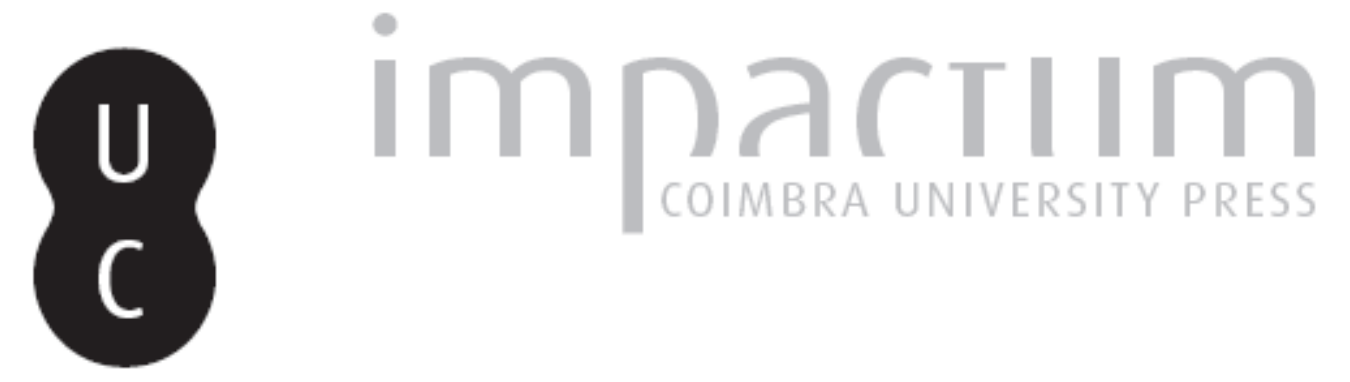

\title{
[Recensão a] SCHWARTZ, Stuart B. - All can be saved: religious tolerance and salvation in the lberian Atlantic world
}
Autor(es):
Silva, Hugo Ribeiro da
Publicado por: Centro de História da Sociedade e da Cultura
URL persistente:
URI:http://hdl.handle.net/10316.2/39588
DOI:
DOI:http://dx.doi.org/10.14195/1645-2259_9_13

Accessed : $\quad$ 26-Apr-2023 16:33:27

A navegação consulta e descarregamento dos títulos inseridos nas Bibliotecas Digitais UC Digitalis, UC Pombalina e UC Impactum, pressupõem a aceitação plena e sem reservas dos Termos e Condições de Uso destas Bibliotecas Digitais, disponíveis em https://digitalis.uc.pt/pt-pt/termos.

Conforme exposto nos referidos Termos e Condições de Uso, o descarregamento de títulos de acesso restrito requer uma licença válida de autorização devendo o utilizador aceder ao(s) documento(s) a partir de um endereço de IP da instituição detentora da supramencionada licença.

Ao utilizador é apenas permitido o descarregamento para uso pessoal, pelo que o emprego do(s) título(s) descarregado(s) para outro fim, designadamente comercial, carece de autorização do respetivo autor ou editor da obra.

Na medida em que todas as obras da UC Digitalis se encontram protegidas pelo Código do Direito de Autor e Direitos Conexos e demais legislação aplicável, toda a cópia, parcial ou total, deste documento, nos casos em que é legalmente admitida, deverá conter ou fazer-se acompanhar por este aviso.

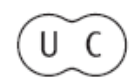



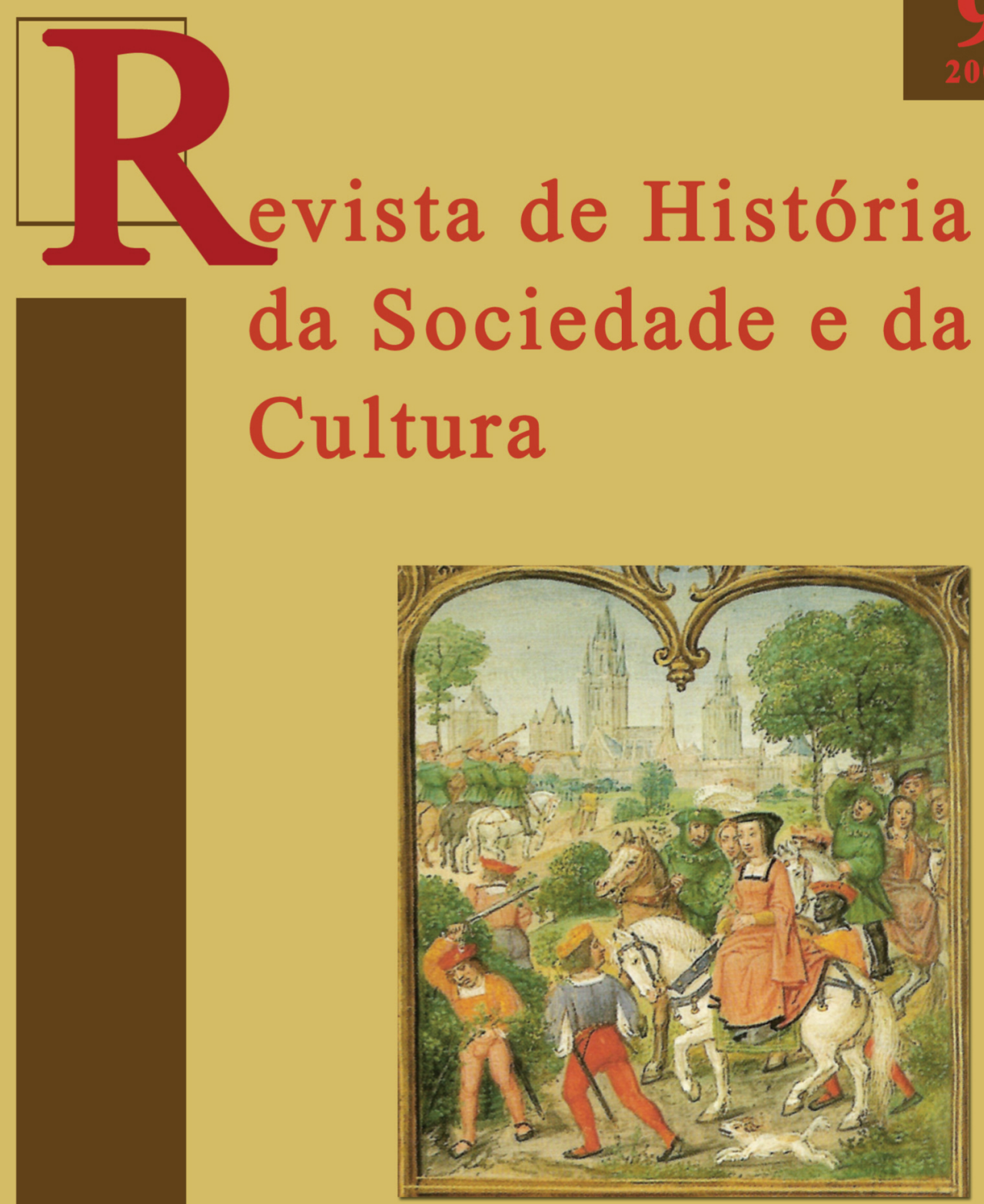

Centro de História da Sociedade e da Cultura Universidade de Coimbra

Coimbra 
orientações: a análise e a interpretação de textos formalmente dirigidos para a formulação de propostas teóricas; a aplicação de ideias e concepções a situações concretas (o uso prático, sempre mais versátil e nem sempre coerente); as meta-análises que têm como objecto a produção historiográfica. Dos desafios, talvez o mais aliciante seja o de aprofundar a compreensão das grandes unidades políticas ibéricas da Época Moderna no contexto do império e das interinfluências de sentido bipolar que então se geraram.

\section{Fernando Taveira da Fonseca}

Universidade de Coimbra e Centro de História da Sociedade e da Cultura da UC

fertaveira@gmail.com

\section{SCHWARTZ, Stuart B. - All can be saved: religious tolerance and salvation in the Iberian Atlantic world. New Haven: Yale University Press, 2008, 336 p.}

Quando pensamos na História de Espanha e Portugal da Época Moderna, certamente que a ideia de tolerância não é a que nos ocorre em primeiro lugar. Pelo contrário. A imagem que temos é a de uma sociedade católica fechada, sob o olhar atento da Inquisição, protagonista no combate às heresias e outros desvios a uma norma que se procurava impor. Stuart Schwartz, seguindo, aliás, ideias que há alguns anos Henry Kamen havia lançado, resolveu questionar esta verdade quase absoluta da historiografia sobre o mundo ibero-americano, propondo-se identificar atitudes de tolerância (mas também de indiferença ou cepticismo) e relativismo religioso (e moral) naquelas sociedades, sobretudo entre as camadas ditas populares. $\mathrm{O}$ autor pretendeu, assim, analisar opiniões que, embora muito minoritárias, estiveram sempre presentes no mundo católico e, eventualmente, terão permitido o florescimento da tolerância religiosa e a "liberdade de consciência", aspectos fundamentais do mundo moderno ocidental.

Para desenvolver este estudo comparativo (uma das mais-valias do livro), o autor dividiu a obra em três partes. As duas primeiras correspondem a duas diferentes geografias (Portugal e Espanha/América), e abrangem sobretudo os séculos XVI e XVII. A terceira parte, com dois capítulos, 
apresenta o epílogo de um longo percurso em direcção a uma maior liberdade religiosa que, pelo menos simbolicamente, o autor faz coincidir com o fim da Inquisição.

Depois de um primeiro capítulo onde apresenta os principais alvos da atenção das Inquisições, quer do ponto de vista espiritual, quer comportamental, Schwartz procura perceber as reminiscências do convívio entre judeus, muçulmanos e cristãos, que durante alguns séculos coexistiram na Península (embora não sem ausência de conflitos entre as diversas comunidades). Ou seja, procura identificar a persistência de outros modos de pensar, numa altura em que Portugal e Espanha deixam de acolher outros credos que não o católico romano. $\mathrm{O}$ autor procura confirmar as suas hipóteses recorrendo a alguns exemplos que surgem entre os processos inquisitoriais. Cristãos-velhos e "conversos" expressavam, por vezes, as suas dúvidas perante algumas das certezas da Igreja e dos inquisidores, e demonstravam a abertura a outros credos. Este relativismo religioso revelava ainda a existência de um conjunto de outras ideias dissidentes, que os afastava dos dogmas da Igreja, mesmo sob a ameaça dos instrumentos disciplinadores que estavam ao alcance daquela instituição: muitos eram aqueles que tinham dúvidas profundas sobre aspectos como a eficácia dos santos, a natureza da Eucaristia ou a ideia da Trindade. Mas tal relativismo ou tolerância surgiriam também porque, por vezes, o perseguido pela Inquisição era um bom vizinho, amigo ou companheiro de negócios. O facto de ser judeu, luterano ou calvinista era irrelevante. Como tantas vezes se afirma ao longo do livro, "cada um pode salvar-se na sua lei". O último capítulo desta primeira parte é dedicado a Portugal, abordando sobretudo a questão dos cristãos-novos, já que eles foram uma das principais preocupações da Inquisição portuguesa. Além de referir o pensamento do padre António Vieira, Schwartz deixa-nos a história de André Lopes, um mercador de lã, casado com uma cristã-nova, sentenciada pela Inquisição. Lopes não se inibia de falar publicamente contra aquele Tribunal, e em defesa dos cristãos-novos. Um exemplo de que a crítica popular à acção do Santo Ofício também existia.

A segunda parte, dedicada à América espanhola e portuguesa, embora com os mesmos objectivos que a anterior, tem em conta os diferentes contextos sócio-culturais que foram sendo criados no Novo Mundo e os desafios que este colocou à ortodoxia religiosa. Schwartz revela uma grande 
preocupação em descrever aqueles contextos, pois eles são um dos factores que contribuíram para o surgimento de atitudes de tolerância, de relativismo e também de sincretismo religiosos. Ali, às populações indígenas juntaram-se católicos, protestantes e cristãos-novos, europeus e africanos. Afastados dos principais centros de poder e perante uma estrutura administrativa incipiente, muitos foram aqueles que viram na América um território onde poderiam viver uma maior liberdade. Além destes aspectos havia o facto de muitos dos espanhóis e portugueses que iam para a América terem tido experiências enquanto soldados, mercadores, peregrinos ou viajantes, pelo que o seu contacto com diferentes realidades religiosas e sócio-culturais os ter levado (pelo menos a parte deles), segundo o autor, a conceber uma atitude de maior abertura perante o outro.

Os dois capítulos da terceira parte constituem a conclusão do livro. O capítulo 8, centrado sobretudo no século XVIII, apresenta uma sociedade (ou sociedades...) onde as ideias de tolerância se foram tornando cada vez menos minoritárias, ao mesmo tempo que cada vez mais elementos das elites intelectuais passaram a defender uma maior tolerância religiosa. Mas antes de se chegar às correntes iluministas setecentistas, e como Schwartz procurou demonstrar ao longo dos primeiros sete capítulos, já muitos tinham sido aqueles que tinham expressado ideias semelhantes. Alguns argumentando que só Deus sabia qual era a melhor religião; outros considerando que todas elas podiam ser válidas; outros ainda não queriam acreditar que quem vivia segundo a lei natural ou quem realizava boas obras pudesse ser condenado por Deus; outros, por fim, acreditavam que a mensagem de Cristo era de paciência e perdão. E havia, além de todos estes, quem duvidasse da validade de todas as religiões e/ou para quem os credos pessoais e a salvação não eram assunto que os preocupasse. Todas estas pessoas, acredita Schwartz, foram a base da tolerância na qual as ideias do Iluminismo puderam florescer (p. 241). Por fim, o capítulo 9 aborda a questão da tolerância religiosa na Europa da Época Moderna, inserindo assim o presente estudo num quadro analítico mais vasto, que vai para além das "fronteiras" do mundo ibero-americano, acabando, deste modo, por integrar a temática no contexto das lutas entre católicos e protestantes. Ao estabelecer tal comparação com o resto da Europa, Stuart Schwartz conclui que "o que é mais notável acerca destas pessoas enquanto grupo é que nos contextos de 
Espanha, Portugal e colónias Americanas eles parecem ter pouco a ganhar com a sua tolerância. Ao contrário da França, Inglaterra ou Alemanha, onde as divisões confessionais tornaram a vida quase insuportável, ou lugares como a Holanda e Polónia, onde se podiam alcançar vantagens políticas e económicas por causa da tolerância, no mundo hispânico o contexto de uma única religião de "Estado" não prometia qualquer benefício imediato para a tolerância” (p. 250).

Estamos, pois, perante uma obra ambiciosa e arriscada, cuja maior força assenta na questão principal que o autor se propôs desenvolver, mais até do que nos resultados, conseguidos ou não. São as hipóteses e objectivos lançados pelo autor que fazem com que este livro mereça atenção. Ao contrário do que se tem feito até agora, o autor olhou para as fontes - sobretudo processos da Inquisição - e colocou-lhes novas questões: por exemplo, perante o que os inquisidores catalogaram como heresia, a historiografia estudou heresias; perante o que os inquisidores classificaram como comportamentos sexuais imorais, os historiadores estudaram desvios, pecados ou crimes. Pois Stuart Schwartz, perante as mesmas fontes viu tolerância e relativismo religioso, viu homens e mulheres que não se sujeitaram aos esforços disciplinadores da Igreja (e do "Estado"). Perante tal abordagem, somos conduzidos, também nós, a relativizar. A relativizar a imagem de uma certa homogeneidade de pensamento e acção que a historiografia nos tem oferecido sobre a sociedade ibérica. A olhar para esta sociedade de uma outra forma, embora sem nunca perder de vista que estamos perante casos minoritários. Mas, como o próprio autor enuncia logo na Introdução, não merecem estes casos, por mais particulares que sejam, serem conhecidos, analisados e compreendidos?

Aliás, é grande e bem conseguido o esforço em compreender os exemplos apresentados, recorrendo a um importante exercício de contextualização, que é um dos aspectos mais importantes da obra. Além do mais, há uma importante, e constante, crítica de fonte, pois Schwartz sabe bem das dificuldades que o tipo de documentos que utiliza levanta ao historiador. A todas (ou quase todas) as dificuldades, potenciais dúvidas e cepticismos ele procura responder, e antever, desde a Introdução ao último capítulo. Schwartz conhece as "armadilhas" que um estudo deste tipo pode encontrar. As dúvidas que ele prevê no leitor, terão sido as dúvidas do historiador. 
E as reflexões deste, transmitidas àquele, procuram sossegar ambos, dando origem a uma obra de grande solidez metodológica.

Contudo, embora no último capítulo (p. 249-250) refira alguns dados (quantitativos até) que procuram dar maior sustentabilidade a todo o argumento, afirmando que um grande número daqueles que expressavam atitudes de tolerância eram cristãos-velhos (espanhóis ou portugueses), a verdade é que muitos dos exemplos apresentados ao longo do livro referem-se a outros europeus, que não da Península, ou a cristãos-novos ou mouriscos, bem como a indivíduos que ao longo da sua vida tiveram contactos com distintas realidades, quer na Europa, África ou América. Ao leitor fica a dúvida de saber por que é que então não apresentou mais exemplos de cristãos velhos. Já que tinha essas informações, por que não introduzi-las no texto, reforçando assim a tese que, afinal, queria provar? Ainda relativamente aos exemplos apresentados, surge um número significativo de clérigos, mas, com a preocupação de contextualizar a história de vida de alguns deles, algumas questões deixaram de ser levantadas ou não foram suficientemente desenvolvidas. Por exemplo, a Inquisição, perante determinada proposição herética, pronunciava penas idênticas quer se tratasse de um leigo ou de um clérigo? Por outro lado, porquê, num trabalho sobre tolerância e relativismo religioso, dar tanto destaque às questões da sexualidade, mais do que às questões de superstição/magia? É verdade que estas também estão presentes, mas num trabalho com os objectivos deste talvez pudessem ter tido maior destaque, até porque é extensa a bibliografia europeia sobre a temática (e que o autor conhece, como se vê na bibliografia citada). Por último, talvez o carácter monolítico das fontes utilizadas pudesse ter sido amenizado com o recurso a outra documentação, nomeadamente a produzida por outra instância de vigilância e disciplinamento social: as visitas pastorais realizadas pelos bispos. Embora as preocupações e atribuições dos prelados neste campo fossem distintas das do Santo Ofício, talvez tivesse valido a pena explorar esta fonte.

\section{Hugo Ribeiro da Silva}

Bolseiro do Ministério dos Negócios Estrangeiros Português, da FCT e doutorando no Instituto Universitário Europeu - Florença hugo.silva@eui.eu 